* Mestrando em Direito pela Faculdade de Direito de Ribeirão Preto da Universidade de São Paulo (FDRP/USP). Graduado em Direto pela Faculdade de Direito de Ribeirão Preto da Universidade de São Paulo (FDRP/USP). Pesquisador do Instituto Tecnológico de Aeronáutica (ITA). Professor do Curso de Pós-Graduação em Direito Empresarial da Escola Superior de Direito (ESD). Email: raphael.andrade.silva@usp. br.

** Doutorando em Economia pela Universidade de Brasília (UnB). Professor da Universidade Católica de Brasília (UCB). Email: matheus.paiva@ucb.br

*** Doutor e Livre-Docente em Direito pela Universidade de São Paulo (USP).

Professor Associado da Universidade de São Paulo - Faculdade de Direito de Ribeirão Preto (USP/FDRP). Email: gsd@usp.br.

\section{DESAFIOS JURÍDICO-REGULATÓRIOS \\ E ECONOMIA COMPARTILHADA: \\ ELEMENTOS PARA UMA REFLEXÃo \\ Crítica}

Legal and Regulatory Challenges AND SHARING ECONOMY: ElEMENTS FOR A CRITICAL ANALYSIS

\author{
Raphael Andrade Silva* \\ Matheus Silva de Paiva ** \\ Gustavo Saad Diniz***
}

Como citar: SILVA, Raphael Andrade; PAIVA, Matheus Silva de; DINIX, Gustavo Saad. Desafios Jurídico-Regulatorios e Economia Compartilhada: Elementos para uma Reflexão Crítica. Scientia Iuris, Londrina, v. 21, n. 2, p. 98-125, jul. 2017. DOI: $10.5433 / 2178-8189.2017 \mathrm{v} 21 \mathrm{n} 1 \mathrm{p} 98$. ISSN: 2178-8189.

Resumo: Nos últimos anos, assiste-se a um fenômeno de crescimento exponencial de novos modelos de negócios, usualmente referidos como disruptivos, próprios do que se tem chamado, sem absoluta homogeneidade terminológica, de "economia compartilhada". Tais modelos parecem não se ajustar perfeitamente às normas jurídicas vigentes na maioria dos ordenamentos, reclamando, portanto, tratativa diversa, atenta às suas particularidades. Deste 
modo, o artigo busca oferecer elementos para uma reflexão crítica a seu respeito, permitindo que formuladores de políticas públicas e operadores desempenhem suas tarefas de forma mais consciente e técnica, beneficiando, em última instância, a sociedade como um todo.

Palavras-Chave: Economia compartilhada. Economia colaborativa. Regulação. Inovação.

Abstract: In the past few years, a widespread phenomenon of exponential growth of new business models took place, usually characterized as disruptive. The proper term for this concept, which has no absolute terminological homogeneity, is the "sharing economy". These models do not fit perfectly within the existing rules of most legal systems; thus, the need for a different approach that contemplates all of its distinctive features. In this sense, this paper seeks to offer elements for a critical analysis, therefore allowing policymakers and practitioners to perform their tasks more consciously, ultimately benefiting society as a whole.

Keywords: Sharing economy. Collaborative economy. Regulation. Innovation. 


\section{INTRODUÇÃO}

É ainda incipiente o fenômeno de ascensão da chamada "economia compartilhada", também referida como "economia colaborativa". Seus efeitos, contudo, já se fazem sentir em diversos locais ao redor do globo: importantes transformações em mercados há muito tempo consolidados, como o de taxi e de hotelaria, bem como incógnitas postadas aos legisladores a respeito da necessidade - e maneira adequada - de se regular esses novos mercados, são questões que, de já, se apresentam com muita intensidade (KOOPMAN; MITCHELL; THIERER, 2015, p. 530).

Nessa linha, o presente artigo tem como objetivo principal analisar alguns pontos específicos a respeito do atual debate. Iniciase, assim, com uma breve descrição do que se entende, atualmente, por economia compartilhada; em sequência, passa-se à discussão de alguns elementos essenciais às novas realidades, suscitando a questão da adequação dos modelos tradicionais à economia compartilhada; apresenta-se, também, como a dogmática jurídica tem enfrentado questões referentes à inovação, apontando-se para uma urgente necessidade de desenvolvimento científico na área; por fim, conclui-se pela necessidade de respostas mais informadas e racionais por parte dos tomadores de decisões, que não somente apliquem, de forma cega, modelos regulatórios concebidos sob premissas fundamentalmente diferentes das atuais.

\section{ECONOMIA COMPARTILHADA: CONCEITUAÇÃO E RETROSPECTO RECENTE}

A bem da verdade, as práticas da economia compartilhada não são exclusivas do presente século (GAUTHIER, 2016, p. 13). Pelo 
contrário, como bem apontam alguns, as raízes desse fenômeno são históricas - no entanto, seus efeitos se tornaram diluídos com o advento e consolidar da sociedade consumerista (RANCHORDÁS, 2015, p. 456). O que visualizamos agora é, portanto, o reemergir desse modelo de relacionamentos sociais e negociais, propiciado pelas plataformas tecnológicas que conectam, de maneira simples, rápida e barata, pessoas que, de outra sorte, não se conheceriam.

Entretanto, não se pode ignorar a rápida ascensão de recentes modelos de negócio orientados pela economia compartilhada. Representantes como Uber e Airbnb operam, hoje, em centenas de locais ao redor do globo, tendo fidelizado um sem número de clientes - razões, inclusive, para seus bilionários valores de mercado ${ }^{1}$.

Dessa rápida ascensão, no entanto, não resultou um acompanhamento dogmático, pari passu, apto a conceituar, de forma homogênea, essa nova realidade. Assim, nem mesmo a expressão "economia compartilhada" é uníssona, havendo aqueles que preferem “economia colaborativa", "peer-production economy” ou, ainda, "peerto-peer economy"2.

No entanto, conforme apontam Koopman, Mitchell e Thierer

1 Para uma interessante avaliação de valores de mercado das principais startups, vejase http://graphics.wsj.com/billion-dollar-club/.

2 Assim aponta Katz (2015, p. 1.068): "There is no standard definition of the sharing economy [...] Many have argued that "sharing" is not an accurate description of P2P service models, in part because users exchange money [...] Other authors have framed the sharing economy as a new form of sustainable consumption and see the sharing economy as a societal shift to an access model rather than an ownership model". Por razões de tal ordem, utilizaremos as expressões "economia compartilhada" e "economia colaborativa" com significação idêntica no presente artigo.

No mesmo sentido, Gauthier (2016, p. 12) assim aduz: "En este contexto se han difundido diversas denominaciones para referir a un fenómeno que se encuentra en pleno desarollo: "economía compartida", "consumo compartido", "peer to peer", "economía colaborativa", "consumo colaborativo", "economía de las aplicaciones", etc.. Quizás ninguna de las anteriores denominaciones por si sola haya logrado capturar la diversidade de la disrupcíon, aunque está claro que la demanda de esta forma de trabajar y consumir es profunda". 
(2015, p. 531), é sugestivo pensar a economia compartilhada como qualquer ambiente de mercado que reúna redes distribuídas de indivíduos para compartilhar ou trocar ativos que, de outra forma, encontrar-se-iam subutilizados ${ }^{3}$. Dessa forma, essa nova realidade englobaria todas as espécies de bens ou serviços, compartilhados ou trocados por utilidades, passíveis ou não de avaliação monetária. Na esteira do indicado por Katz (2015, p. 1.069), a literatura tem classificado a economia compartilhada como uma "inovação disruptiva", associando-a a produtos, serviços e modelos de negócios que recombinam velhas tecnologias para estabelecer novos mercados e que, portanto, "rompem" com os agentes econômicos incumbentes.

Nessa linha, a economia compartilhada configura, de fato, a base de disruptivos modelos de negócios, cujo surgimento se fez possível em virtude do advento de novas tecnologias (BARRY; CARON, 2015, p. 69). $\mathrm{O}$ ato de compartilhar, efetivamente, se tornou mais fácil com o desenvolvimento recente da tecnologia social comunicativa, a qual permite a conexão de indivíduos absolutamente desconhecidos, gerando, dentre outros, um incentivo à colaboração.

Em adição, parece haver um movimento no sentido de tornar mais barato compartilhar do que ser proprietário, o que leva alguns a afirmarem a existência de verdadeiro rompimento do paradigma clássico de que seria necessário possuir - em termos de direitos de propriedade - um determinado bem ou serviço para poder usufruir do mesmo (GAUTHIER, 2016, p. 12).

As externalidades positivas podem favorecer o ambiente hospedeiro da economia colaborativa. Quando algum agente econômico

$3 \mathrm{Na}$ verdade, a própria natureza peer-to-peer de muitos dos negócios da economia compartilhada e que proporciona a possibilidade de que os participantes lucrem por meio de bens subutilizados (KATZ, 2015, p. 1.073). 
realiza uma ação que gera benefício para outros, sem que tal benefício seja remunerado, há, então, um efeito colaborativo. Este efeito pode incentivar os que recebem a retribuí-lo, desenvolvendo uma rede compartilhada de benefícios recíprocos (MANKIW, 2015, p. 200).

Alguns dos mais importantes exemplos de externalidades que contribuem para o florescimento da economia colaborativa são os chamados spillovers. Estes elementos compreendem os efeitos econômicos não intencionais (efeitos colaterais) que ocorrem devido a choques econômicos iniciais. Isto significa que, quando há concentração de algum ativo valioso (insumo, tecnologia, força de trabalho, terra, informação, infraestrutura, capital financeiro etc.) em uma determinada região, o simples fato de hospedar tais recursos faz com que, nesta região, se desencadeiem efeitos de transbordamento. Por exemplo, uma cidade com alta densidade populacional oferece incentivos para a atração de "firmas". Esta atratividade, por sua vez, aumenta a competição e estimula o processo de inovação e de transferência de conhecimento, criando um ambiente favorável para o auto reforço e, portanto, para a prosperidade econômica (FOCHEZATTO; VALENTINI, 2010, p. 246).

Quando estes efeitos colaterais são positivos, oriundos de externalidades, interações sociais, equilíbrio geral etc., o resultado beneficia a economia como um todo (ANGELUCCI; DI MARO, 2015, p. 5). Esses benefícios recaem sobre a economia por diversas formas, seja pela redução dos custos de produção, pelo aumento no acesso de recursos físicos ou humanos, pelo aperfeiçoamento na comunicação, na formação de redes de contatos e nas economias de escala, dentre outros ${ }^{4}$. Neste sentido, comunidades dotadas de spillovers positivos tendem a

4 Para maior aprofundamento sobre os efeitos desencadeados pelos spillovers, ver Marshall (1890), Fujita e Thisse (1996) e Fochezatto e Valentini (2010). 
formar um ambiente mais propício ao desenvolvimento da economia colaborativa.

Muito embora o modelo seja novo, como bem ressalta Ranchordás (2015, p. 416), a ideia basilar que lhe dá sustentação é relativamente simples: os agentes econômicos irão compartilhar bens e serviços quando os custos de transação relacionados à coordenação de atividades econômicas dentro de um determinado grupo ou comunidade for baixo.

\section{ECONOMIA COMPARTILHADA: PRINCIPAIS ASPECTOS E BENEFÍCIOS}

A existência da economia colaborativa somente se faz possível em razão de dois elementos essenciais: (i) a existência de ativos compartilháveis que sistematicamente apresentam capacidade em excesso; e (ii) a predominância de atitudes ou motivações de compartilhamento (RANCHORDÁS, 2015, p. 416).

É comumente apontado que a nova realidade da economia compartilhada é capaz de gerar valor em, ao menos, cinco aspectos substanciais (KOOPMAN; MITCHELL; THIERER, 2015, p. 531-532).

$O$ primeiro desses aspectos diz respeito ao uso mais produtivo e eficiente dado aos ativos subutilizados, também referidos como "capital morto"s. O segundo aspecto relaciona-se com o fato de que estes novos marketplaces, ao reunir inúmeros compradores e vendedores, promovem maior competitividade entre as vertentes de oferta e demanda, permitindo, assim, maior especialização e complexidade econômica. O terceiro aspecto tem origem na redução dos custos de transação promovida pela

5 Para uma discussão a respeito da ideia de "capital morto" ("dead capital"), veja-se De Soto (2001). 
economia compartilhada. Isso porque esses novos modelos diminuem substancialmente o custo de se encontrar um parceiro para realizar as trocas, bem como minoram, de forma importante, os custos relacionados à negociação dos termos ajustados entre as partes e, além, permitem um maior monitoramento da contraparte (KATZ, 2015, p. 1.075).

Aliás, é justamente desta linha de maior monitoramento que surgirá o quarto aspecto: ao permitir, em geral, o rating dos usuários por outros usuários, que com o primeiro já concluíram negócios anteriores, o modelo oferece, aos novos participantes, maiores níveis de informação. Na pior das hipóteses, diminui-se, significativamente, as imperfeições decorrentes da assimetria informacional entre fornecedores e consumidores.

Outro importante elemento que auxilia na redução dos custos de transação é a padronização dos negócios e o oferecimento de garantias de qualidade e segurança. Medidas no sentido de padronizar as trocas incluem, por exemplo, interfaces amigáveis e uniformes, sistemas de busca baseados na localização do usuário, mecanismos de comparação de preços, análise da utilização de contas, históricos de pagamento e ferramentas de agendamento e reserva. No tocante às garantias, mencionase o oferecimento de seguros, canais de atendimento e reclamação dos usuários, políticas de cancelamento e reembolso, filtragem de background dos usuários e os já mencionados sistemas de reputação (KATZ, 2015, p. 1.075).

Desta forma, por meio da combinação dos recursos acima brevemente mencionados às suas plataformas, os modelos de negócio da economia compartilhada permitem aos usuários a negociação em maior escala, encorajando, inclusive, participantes casuais a entrarem no mercado. Assim, estas plataformas facilitam a realização de negócios 
que, de outra sorte, provavelmente jamais aconteceriam em virtude dos altos custos de transação associados.

Por fim, o quinto - e talvez mais sensível - aspecto, diz respeito ao oferecimento de melhores serviços e produtos àqueles consumidores que, com base na situação atual, são tratados de forma insatisfatória pelos players incumbentes, muitas vezes em razão da própria captura dos entes reguladores pelos agentes de mercado, que, não raro, se tornam despreocupados com a qualidade de seus serviços e produtos em virtude de sua maior proteção regulatória ${ }^{6}$.

Muito embora, em uma primeira análise, a economia compartilhada apresente benefícios ${ }^{7}$, pode-se verificar, na prática, o crescente levantar de bandeiras no sentido contrário à sua propagação. Esse movimento, originado, talvez, na incompreensão de seus fundamentos e modus operandi, tem ecoado em diversos locais do mundo.

Para ilustrar o mencionado acima, considere-se o caso do aplicativo Uber. Em importantes cidades europeias, como, por exemplo, Berlim e Bruxelas, viu-se a proibição completa da utilização desse sistema de transporte de passageiros ${ }^{8}$.

\section{DESAFIOS REGULATÓRIOS: POR QUE E COMO REGULAR?}

6 Ilustrando a situação das plataformas de transporte de passageiros, Rassman (2014, p. 99) assim afirma: "Rideshare's growing consumer base demonstrates that it is, at least for the foreseeable future, here to stay. [...] Rideshare has responded to consumer demand in a long-stagnant market [...]".

7 Para uma análise detida sobre os vários benefícios da economia colaborativa, tanto sob o ponto de vista da oferta como da demanda, veja-se Dyal-Chand $(2015$, p. $256-$ 259).

8 Como aponta Ranchordás (2015, p. 418-419), na Alemanha chegou-se a compreender que o Uber representava, de fato, concorrência desleal à indústria de taxi. Essa posição foi esboçada em decisão da Corte Distrital de Frankfurt. Em Londres também foram intensos os debates a respeito da viabilidade e legalidade da presença do Uber no mercado. Recentemente, o órgão regulador do trânsito naquela cidade ("Transport for London" - TfL) entendeu que o aplicativo Uber para smartphones poderia ser considerado um taxímetro e que taxímetros não eram de utilização exclusiva de carros licenceados, removendo importante barreira à presença da Uber Technologies naquele mercado. 
De acordo com Morey (2015, p. 1), falhas de mercado são situações inerentes ao mercado que fazem com que a alocação de equilíbrio seja ineficiente. Ou seja, são cenários nos quais, muito embora seja possível aumentar o bem-estar de algum agente econômico, por meio das trocas, sem prejudicar os demais, tais trocas são impossíveis de serem realizadas. Neste sentido, diz-se que o mercado não conduziu a economia para uma situação de Ótimo de Pareto.

Existem diversas razões para a existência de falhas de mercado. Por exemplo, sob um contexto de informação assimétrica, não há mais condições para se sustentar o Primeiro Teorema do Bem-Estar. Este Teorema diz que, se os indivíduos conhecem todos os preços da economia sob uma estrutura de mercado perfeitamente competitiva, então a alocação de mercado é Pareto ótima.

Mas, se existe o problema da assimetria de informação, já não se pode concluir que as ações individuais, tomadas no contexto de mercados perfeitamente competitivos, conduzirão a economia para um equilíbrio ótimo no sentido de Pareto. Neste ambiente de assimetria de informação, onde alguns agentes possuem mais informações que os demais, surgem situações nas quais determinados indivíduos se comportam de maneira oportunista, ocasionando escolhas adversas e perda de bem-estar para os demais (JEHLE; RENI, 2011, p. 379).

Uma outra falha de mercado pode ser verificada quando o bemestar de um agente, ou de um grupo deles, depende de uma atividade que está sob o controle de outro agente ou de outro grupo de indivíduos. $\mathrm{Na}$ ciência econômica, tal situação consiste, justamente, na já apresentada externalidade, a qual pode ser positiva ou negativa. Se positiva, a ação dos agentes econômicos, direcionada às atividades sobre as quais detêm controle, provoca aumento do bem-estar dos demais. Se negativa, esta 
ação gera perda de bem-estar para o restante da coletividade. Este efeito negativo não é socialmente desejável, pois reduz o bem-estar social.

Os dois exemplos revelam situações onde o mercado, operando sem a presença do Estado, não é, em todo caso, capaz de conduzir a sociedade para a melhor situação possível. Ainda que soluções privadas possam ser utilizadas e efetivas, como confirma o Teorema de Coase ${ }^{9}$, em qualquer um dos casos, há uma lacuna que pode ser ocupada pelo Estado (MANKIW, 2015, p. 202). A presença de uma autoridade altera substancialmente a operacionalidade do mercado, pois pode coagir os indivíduos a implementarem comportamentos socialmente desejáveis, oferecendo instrumentos para reduzir as falhas de mercado, auxiliando na realocação dos recursos disponíveis e, portanto, conduzindo a economia para um novo equilíbrio mais eficiente.

A abordagem tradicional da regulação econômica se ancora sob a análise convencional do bem-estar individual. Desta forma, por esta perspectiva, é possível mensurar o nível de bem-estar social antes e depois da regulação estatal e, por fim, compará-los. Nesta direção, uma vez calculados os níveis de bem-estar social, seria relativamente simples avaliar se a regulação do Estado é recomendável. Contudo, com a transformação da sociedade moderna, a metodologia empregada para avaliar as regulações também se desenvolveu. Neste sentido, destaca Fiani (1998, p. 12):

Progressivamente não apenas os limites do campo regulatório começaram a ser questionados, como até mesmo o sentido da regulação foi objeto de

9 Em elucidativa síntese: "The Coase theorem says that private economic actors can potentially solve the problem of externalities among themselves. Whatever the initial distribution of rights, the interested parties can reach a bargain in which everyone is better off and the outcome is efficient" (MANKIW, 2015, p. 210). 
revisão crítica. Neste processo houve um passo teórico fundamental. À análise das falhas de mercado a teoria econômica veio a acrescentar, a partir dos anos setenta, a análise das "falhas de governo". Compreender adequadamente o conceito de falhas de governo não é tarefa tão simples como o estudo das falhas de mercado: enquanto o último se fundamenta em uma discussão dos obstáculos à consecução de um ótimo de Pareto pelo mercado (utilizando como ferramenta a análise de equilíbrio parcial ou geral, já solidamente estabelecidas na tradição da teoria econômica), a análise de falhas de governo obviamente não pode recorrer ao mesmo tipo de suporte teórico-analítico, pelo simples fato de que a atuação do governo não é orientada por profit-seeking.

Assim, diversos conceitos foram construídos - grupos de interesse e pressão, rent-seeking, dentre outros - para aprimorar a avaliação regulatória e abarcar as novas situações e os novos mercados que surgiram com o desenvolvimento do capitalismo ${ }^{10}$. Nesta linha, esta evolução na literatura mostra que o enfoque ideal encerra uma avaliação dos objetos da economia compartilhada por uma perspectiva moderna, um tanto quanto diferente da tradicional, uma vez que as ferramentas técnico-analíticas convencionais não são suficientes, ainda que úteis, para, de um lado, compreender toda a complexidade da economia de redes e, de outro, contabilizar todos os efeitos daí decorrentes.

As práticas da economia compartilhada suscitam questões que desafiam os reguladores em base diária, tornando clara a tensão entre, de um lado, a necessidade de encorajar a inovação e, de outro, o objetivo

10 Para maiores informações sobre o assunto ver Tollison (1982), Benson (1984) e Olson (1995). 
de proteção dos consumidores.

Uma primeira razão para a confusão geralmente provocada pelas empreitadas regulatórias diz respeito ao fato de que a economia colaborativa é fenômeno novo e distinto, cujos pressupostos parecem diferir em muito dos tradicionalmente assentados em ambientes capitalistas atuais (DYAL-CHAND, 2015, p. 244). Essas novas realidades de negócios frequentemente tornam opacas e insuficientes variadas classificações e conceitos jurídicos, do que resultam áreas legais cinzentas, gerando verdadeira incerteza regulatória (KATZ, 2015, p. 1.068).

Além disso, como bem aponta Ranchordás (2015, p. 420), não se pode reduzir o debate à (i) proteção de pequenas, porém inovadoras startups; e (ii) legisladores, reguladores e grandes indústrias interessadas em manter seus clientes. Isso porque, como já se viu, diversas dessas startups estão longe de serem pequenos players. O verdadeiro embate se dá, portanto, entre (i) o interesse de estimular a inovação; e (ii) a necessidade de proteção do público em geral dos potenciais malefícios que acompanham essa inovação.

Após apresentar a ideia de que, a despeito do fato de as razões clássicas para a introdução da regulação relacionarem-se com a necessidade de proteção dos consumidores, Koopman, Mitchell e Thierer (2015, p. 544) argumentam que desse fato não decorre, invariavelmente, que referidas regulações tenham atingido seus objetivos ou mesmo que sua necessidade persista nos dias de hoje. Nessa linha, sustentam os autores que a evidência empírica parece demonstrar que existe um conjunto de elementos a priori melhor habilitado, em muitos casos, a resolver problemas do que a própria regulação.

Em sintonia com o exposto, é imperativo que os reguladores 
olhem para o fenômeno da economia compartilhada, de fato, como uma nova modalidade de negócios. A principal implicação prática dessa percepção é que não se pode pretender incidir, às novas realidades, de forma idêntica, preceitos legais aplicáveis a práticas comerciais equivalentes. Se é verdade que muitas dessas realidades são razoavelmente análogas a produtos e serviços tradicionais, já conhecidos pelos formuladores de políticas, é igualmente certo que, no mais das vezes, diferem elas substancialmente do que já existe, não se amoldando adequadamente ao panorama regulatório estabelecido (KATZ, 2015, p. 1.076).

Assim, por exemplo, a decisão de proibição de utilização do aplicativo Uber, em razão da não conformidade de sua estrutura e operação com a legislação municipal de transporte individual de passageiros na modalidade taxi é não somente insatisfatória, mas, também, simplista (RANCHORDÁS, 2015, p. 474-475). Consistente com a sugestão de Posen (2015, p. 426), ao invés de submeter o Uber e outros modelos de negócios semelhantes a corpos regulatórios ultrapassados, inconsistentes com sua realidade, formuladores de políticas devem desenhar novas regras. Talvez por esta razão muitas das tentativas empreendidas, por exemplo, nas várias jurisdições estadunidenses se revelaram pouco efetivas (RASSMAN, 2014, p. 84).

A ideia parece harmonizar-se com a proposta alinhavada por Ashford, Ayers e Stone (1985, p. 422), para quem, ao criar uma atmosfera condutora de inovação, os reguladores devem, inicialmente, investigar a capacidade inovadora do setor econômico em questão. Nesta esteira, a análise deveria focar, principalmente, na "dinâmica inovadora", ao invés de cingir o exame a uma proposta estática, centrada na capacidade tecnológica já existente.

$\mathrm{O}$ método requer, portanto, extensa investigação a respeito 
da história e padrões de inovação inerentes ao setor, avaliação das capacidades tecnológicas de setores relacionados e que tenham incentivos para fornecer tecnologia substituta e as respostas desses últimos a regulações previamente estabelecidas.

\section{DESAFIOS JURÍDICOS}

O enfrentamento, pela literatura jurídica, de questões relativas à economia compartilhada é extremamente recente e, por isso, escasso. Também é recente a interação entre o Direito e o próprio fenômeno da inovação - muito embora as sociedades e os indivíduos invistam, anualmente, montantes substanciais em pesquisa e desenvolvimento (“P\&D”), pouquíssimo se tem pesquisado a respeito, especialmente no âmbito jurídico.

A relação é mesmo das mais complicadas. Por muito tempo compreendeu-se que a melhor forma de o Direito incentivar e, mais, promover a inovação era efetivamente se afastando dos temas a ela relacionados. Assim, argumentava-se, pelo menos se reduziria a chance do pior resultado acontecer: o desincentivo à inovação.

É bem verdade que, em algumas situações, a intervenção estatal, ao impor pesados - e, por vezes, injustificados - ônus sobre os agentes econômicos, freia o fluxo de inovação.

No entanto e por outro lado, a absoluta ausência de normas disciplinadoras do fenômeno pode implicar no conflito entre, de um lado, valores outros também tutelados pelo ordenamento e, de outro, a necessidade de inovação. De tudo, o que se entende, hoje, é que um dos possíveis payoffs da relação legislação/regulação e inovação é a facilitação da introdução de novas tecnologias no mercado (RANCHORDÁS, 2015, 
p. 442).

A maneira como legisladores e reguladores visualizam a inovação, compreendem suas particularidades, seus efeitos líquidos sobre os consumidores e outros participantes do mercado e da sociedade em geral e, por fim, disciplinam essa realidade, é de importância inegável. $\mathrm{O}$ ambiente institucional - compreendendo-se, aí, as normas que disciplinam as relações sociais - é, portanto, importante para o desenrolar do caminho de inovação.

$\mathrm{Na}$ verdade, a discussão abaixo apresentada se afigura da maior relevância pelo simples fato de que o panorama institucional acima referido, especialmente quando tomamos a regulação, pode afetar adversamente a inovação em quatro sentidos principais: (i) impondo limitações tecnológicas aos agentes econômicos; (ii) forçando os agentes econômicos a realizar despesas adicionais; (iii) causando incerteza; e (iv) causando atrasos. Explica-se.

Exigências de comando e controle contidas em determinações regulatórias impõem restrições diretas na conduta dos agentes econômicos, impedindo certas formas de inovação mercadológica. Sejam estas restrições passivas, isto é, configuradas por meio de vedações de condutas ou ativas, instrumentalizadas por meio da prescrição de comportamentos, a variável chave a ser investigada é o quão essas exigências restringem a liberdade de adoção, pelos agentes de mercado, de novos produtos e processos que seriam comercialmente bem-sucedidos (STEWART, 1981, p. 1.280).

É insuficiente, contudo, a compreensão de que deve haver intervenção estatal no sentido de regular e promover a inovação. Essa noção pode ser perigosa e, inclusive, gerar efeitos diametralmente opostos aos desejados, quando desacompanhada de um real interesse 
em compreender, a fundo, quais as implicações práticas trazidas por determinado novo modelo.

A argumentação acima apresentada não deve enganar: até muito recentemente, o assunto inovação, para a literatura jurídica, guardava relação quase que exclusiva com temas associados à proteção da propriedade intelectual e da concorrência. A realidade demanda do jurista, no entanto, muito mais.

$\mathrm{O}$ interesse dogmático em um método que se proponha a compreender, em abstrato, quais os possíveis efeitos decorrentes da aplicação das normas jurídicas sobre a criatividade, o empreendedorismo e a busca pelo desenvolvimento de novas tecnologias é ainda incipiente ${ }^{11}$.

Iniciativas de economia colaborativa transitam entre a atividade pessoal e comercial, pública e privada, desafiando, em certos casos, a própria conceituação de bens e serviços (KATZ, 2015, p. 1.092). Daí surgem inúmeras questões de importância, a ensejar a necessidade de adequação de conceitos e categorias jurídicas cunhados em um contexto fático substancialmente diverso, especialmente porque os modelos de negócio disruptivos tendem a desafiar o binarismo geralmente preferido por legisladores e aplicadores do Direito, situando-se, verdadeiramente, em espaços intermediários ${ }^{12}$.

Em nosso ver, um dos principais pontos que terão de ser enfrentados, talvez especialmente pelo Poder Judiciário, referencia a questão da responsabilidade dos gestores de plataformas peer-to-peer,

11 A respeito de uma vertente denominada Innovation Law, ver Ranchordás (2015, p. 33 e ss.).

12 Neste sentido, assevera, acertadamente, Gauthier (2016, p. 16): “Un primer desafío que enfrentan las empresas que se están desarrollando en el marco de la economía compartida, se vincula con la dificuldad de tener que regirse por reglas o normas de la más diversa índole, concebidas para otro tipo de realidades o negocios y donde a menudo se perciben desajustes tan importantes que las tornan inaplicables en muchos casos". 
tais como aquelas que intermediam o transporte de passageiros, o aluguel de automóveis, a locação de quartos e apartamentos e a prestação de serviços, dentre outros.

Isso porque, como sugere Katz (2015, p. 1.099), alguns pressupostos tradicionalmente estabelecidos para relações de consumo, como, por exemplo, a vulnerabilidade e hipossuficiência dos consumidores, a posição superior de barganha dos fornecedores e o tratamento destes como agentes aptos a implementar medidas de mitigação e gestão de riscos a um custo mais baixo, parecem não se sustentar, quando criticamente examinados.

Os "fornecedores" - e aqui valemo-nos do termo sem a acepção técnica fornecida pela legislação consumerista, até porque a adequação do conceito deverá ser objeto de estudo singular, em virtude de sua importância - atuantes em plataformas de compartilhamento são, geralmente, participantes casuais e informais, operando em escala substancialmente inferior à de seus análogos tradicionais e sem o mesmo expertise (cogite-se, por exemplo, daquele que aluga seu apartamento de um quarto, de um lado, e um hotel, de outro), utilizando, muitas vezes, bens e capital próprio.

Pelo fato de que, na maioria dos casos, tais "fornecedores" estarão em pé de vulnerabilidade com os próprios usuários (isto é, os demandantes), parece insensato exigir, dos primeiros, o mesmo nível de compliance regulatório, submetendo-lhes ao mesmo regime jurídico de seus análogos tradicionais.

Nesta linha de raciocínio, reguladores parecem tentados a estabelecer a responsabilidade indireta das próprias plataformas em virtude de acidentes relacionados às negociações ocorridas em seus ambientes (KATZ, 2015, p. 1.100). A estratégia de esquiva destas 
últimas, naturalmente, é a de albergar-se sob o manto da natureza de mero intermediário neutro, o qual somente facilita a realização de operações entre os usuários do ambiente.

Dentre os vários modelos possíveis de atribuição de responsabilidade aplicáveis aos negócios da economia compartilhada, Katz (2015, p. 1.106) afirma não estar claro qual a melhor proposta para se alocar, de forma adequada, a responsabilidade entre os "fornecedores", usuários (demandantes) e as próprias plataformas.

Isto porque os marketplaces geralmente não são absolutamente passivos, exercendo, ao menos em algum grau, controle sobre os "fornecedores" e sobre as próprias transações. Além disso, quase todas as plataformas têm algum tipo de interesse financeiro nas operações, usualmente pelo recebimento de determinado percentual destacado sobre o valor do negócio, fatores estes que sugerem, de antemão, a inadequação de um sistema de irresponsabilidade absoluta.

Por outro lado, impor aos agentes disruptivos deveres ativos de extenso monitoramento da aquiescência de "fornecedores" e usuários com a legislação parece implicar em altíssimos custos de conformidade. Vê-se, assim, não haver fórmula simplista, de modo que esta dificuldade tende a se irradiar, com maior ou menor intensidade, para todas as demais questões polêmicas ${ }^{13}$.

$\mathrm{Na}$ sequência, alguns elementos devem necessariamente ser levados em consideração no debate a respeito da regulação das realidades de economia colaborativa.

O primeiro deles diz respeito à incerteza. A incerteza, por óbvio, é um dado intrínseco ao processo de inovação. No entanto, graus elevados

13 Para algumas sugestões de propostas regulatórias para as realidades da economia compartilhada, veja-se Katz (2015, p. 1.109-1.126). 
de incerteza têm por consequência justamente a inatividade criativa. Os agentes econômicos serão, de fato, relutantes em inovar caso haja fundadas dúvidas de que seus novos modelos de negócios serão aceitos pelos legisladores e reguladores (STEWART, 1981, p. 1.280-1.281) ou caso haja constantes e incoerentes revisões legislativas ou judiciais a respeito desses modelos.

Também neste aspecto deverá prevalecer a ponderação do regulador, porquanto, conforme sugerem Ashford, Ayers e Stone (1985, p. 426), se, por um lado, alterações frequentes nos requerimentos regulatórios podem frustrar o desenvolvimento tecnológico, por outro, excessivos níveis de estabilidade e certeza também podem ocasionar ociosidade industrial, estimulando, portanto, apenas o desenvolvimento de produtos e serviços que atendam níveis mínimos de exigência legal.

O segundo elemento trata-se da complexidade. É imperativo que reconheçamos que a inovação é fenômeno, processo ou resultado complexo e, como complexo que é, não pode prescindir de soluções orquestradas, orgânicas, conjunturais - ao contrário de soluções simplistas. Nessa linha, para bem disciplinar as novas realidades, necessário será um conjunto de instrumentos, públicos e privados, em que nenhum deles, individualmente tomado, é, a priori, apto a solucionar, de forma definitiva, o problema. De maneira sintética, as destruições criativas usualmente envolvem, em alguma medida, caminhadas em ambientes desconhecidos (WHITT, 2009, p. 524-549).

O terceiro elemento para o qual se chama atenção é a temporariedade ou flexibilidade. Conforme já aduzido, a inovação é fenômeno complexo e permeado, naturalmente, pela incerteza. Dessa forma, qualquer modalidade de legislação e regulação que se pretenda fechada em si mesma estará, inevitavelmente, fadada ao descrédito e 
à inaptidão para disciplinar, de maneira adequada, os fatos sociais e econômicos, em algum momento do tempo.

No entanto, essa última observação não deve desanimar: de toda sorte, sempre foi essa a realidade da normatização de disciplinas relativas, por exemplo, ao direito comercial, onde a lex mercatoria, apoiada nos usos e costumes comerciais se desenvolveu a passos muito mais largos do que sua correspondente positivada.

A solução para esse descompasso, longe de estar definitivamente sedimentada, parece passar por uma certa flexibilidade regulatória, necessária para fazer frente ao contexto de evolução rápida e incerteza, como bem quer Listokin (2008, p. 480-484). Essa flexibilidade, argumentam alguns, será importante no sentido de contribuir para o desenvolvimento de regulações ótimas ${ }^{14}$.

Ao jurista se impõe, portanto, um novo desafio: enfrentar o fenômeno da inovação e as variadas implicações dele decorrentes por outras lentes, além das tradicionalmente utilizadas, a saber a da proteção de direitos de propriedade intelectual e da concorrência.

Muito embora, nas discussões atuais a esse respeito, o instituto, por exemplo, da proteção patentária seja dos primeiros a ocorrer-nos, nem todas as formas de inovação obedecem aos critérios legalmente exigidos para referida proteção. Mais além, argumenta-se que, no âmbito da economia colaborativa, a ausência de proteção de direitos de propriedade intelectual parece não ter diminuído o volume de criatividade (HOESCHELE, 2011) ${ }^{15}$.

14 Para sugestões de soluções regulatórias no sentido da flexibilização, como, por exemplo, a introdução de sunset clauses ou as experimentações de pequena escala, veja-se Ranchordás (2015, p. 451).

15 Nas palavras do autor: "The critical point is that innovation would not stop in the absence of patents. Instead, it would go in different directions, and it would be funded primarily by people and institutions who have an interest in the use value of those innovations, rather than by those who have an interest in their exchange value. This 
Igualmente importante, será imperativo transpor os limites do direito antitruste. A intervenção estatal no sentido de promoção da inovação não pode e não deve ser reduzida a preocupações de ordem concorrencial. É evidente que a inovação é um importante motor de aumento da competitividade entre os agentes de mercado. No entanto, caso o panorama institucional se conforme apenas com esse apontamento e seus desdobramentos, será inevitável sua insuficiência para compreender novos modelos de colaboração.

A ideia central é a de que a inovação pode e deve ser promovida por instrumentos legais que não dizem respeito diretamente à proteção de direitos de propriedade industrial e intelectual e à garantia da concorrência. Esses dois campos, apesar de importantes, são insuficientes para apreender diversas realidades, em especial no que toca à economia colaborativa: iniciativas locais para o empowerment de minorias, a integração de imigrantes ou a conscientização do empresariado sobre responsabilidade social são apenas alguns exemplos de realidades que escapam, por muito, dessas tradições.

Nessa linha, Ranchordás (2015, p. 453-454) menciona, como exemplos reais e aptos a promover a inovação, (i) a introdução do $\operatorname{Start} U p$ Visa Act of 2013, documento legislativo estadunidense que, modificando o Immigration and Nationality Act, buscou atrair empreendedores estrangeiros para suplantar deficiências do mercado daquele país; e (ii) a introdução do StartUp Business Visa, modalidade de visto canadense que poderá garantir possibilidade de residência permanente a empreendedores

would dramatically change who determines what technological innovation happens, making it user-driven rather than seller driven; it would also shift innovation away from merely product innovation and toward process innovation and social innovation. Such innovations include, for example, all the innovations of the "sharing economy" from couch-surfing to P2P car-sharing, that allow people to make more effective use of the resources they already own, while reducing their environmental impacts". 
estrangeiros que cumprirem determinados requisitos.

Em síntese, para que se trace um desenho institucionalregulatório adequado a tal ou qual nova tecnologia emergente, três determinações devem, imperativamente, ser realizadas, levando-se em consideração todas as particularidades acima discutidas, quais sejam (i) qual é a resposta tecnológica desejável para determinado problema identificado (por exemplo, deveria a regulação induzir uma modificação no produto ou processo ou a mera difusão da tecnologia existente?) ${ }^{16}$; (ii) qual é o setor da atividade econômica mais propício a promover a inovação desejada; e (iii) qual é a espécie de regulação que, com maior probabilidade, fornecerá os resultados desejados (ASHFORD; AYERS; STONE, 1985, p. 429).

Como aponta Dyal-Chand (2015, p. 247), a falha conceitual mais grave parece residir, justamente, na incompreensão dos pressupostos fundamentais que orientam os novos modelos de negócios e na consequente falha na percepção de que a economia colaborativa se apoia em instituições essencialmente distintas daquelas do capitalismo tradicional, não se conformando, na maioria dos casos, às categorias e classificações preexistentes. O importante é, contudo, não encarar tal desconformidade de forma pouco pensada e, de plano, relegar os novos modelos de negócios à ilegalidade.

Exemplos de tentativas interessantes podem ser encontrados na legislação do Estado da Califórnia, primeiro a legalizar os serviços

16 Contudo, devemos advertir, com Stewart (1981, p. 1.282), que, se a tecnologia necessária não se encontrar bem estabelecida, consolidada, "devising effective incentives for social invention under command-and-control standards is much more difficult. Regulatory agencies can try to anticipate and thus "force" the state of the art by adopting standards based on a regulatory agency's estimate of the most promising technical opportunities. But if the firms subject to regulation must develop the technology that will achieve those standards, the regulatory agency may suffer serious handicaps in acquiring the information necessary to justify its estimate of the most promising technical opportunities". 
chamados de "peer-to-peer ridesharing", em setembro de 2013, erigindo o conceito legal de "transportation network company" (TNC), classificadas como companhias ou organizações que, operando na Califórnia, fornecem serviços de transporte utilizando plataformas online para conectar passageiros e motoristas que utilizam seus veículos particulares, não comerciais. Igualmente, em junho de 2014, o Estado do Colorado promulgou o "Transportation Network Company Act", diploma que se vale da mesma figura acima apresentada, qual seja a das TNC.

No Brasil, o Município de São Paulo, por meio do Decreto ${ }^{\circ}$ 56.981/2016, regulamentou o uso intensivo do viário urbano municipal para exploração de atividade econômica privada de transporte individual de passageiros de utilidade pública, o serviço de carona solidária e o compartilhamento de veículos sem condutor. Neste mesmo diploma, criou-se a figura jurídica das Operadoras de Tecnologia de Transporte Credenciadas (OTTC), entidades que gerenciam plataformas tecnológicas para a exploração das atividades ali disciplinadas.

\section{CONCLUSÕES}

Apoiando-nos em Katz (2015, p. 1.084), é necessário concluir que regular a economia colaborativa requer um verdadeiro equacionamento de interesses. Autoridades regulatórias devem certificar-se de que as regras estabelecidas protegem, adequadamente, tanto os participantes dessa nova realidade como terceiros que, direta ou indiretamente, com ela se relacionam.

Adicionalmente, não se pode ignorar a relevância desses novos negócios e, via de consequência, a imperatividade de se lhes disciplinar, porquanto sejam veículos aptos a gerar benefícios não 
somente aos consumidores, mas, também, ao próprio Estado, dos quais é exemplo o incremento na arrecadação tributária. Complementarmente, a dinamicidade dos produtos e serviços concebidos poderá, em certos casos, apresentar sérios riscos, merecedores de aguçada atenção.

Como subsídios para uma discussão mais aprofundada, remetemos o leitor a algumas sugestões de Katz (2015, p. 1.109-1.126) que, muito embora exaradas em contexto institucional diferente, parecem servir, se não como objeto para transposição à nossa realidade, ao menos como elementos para um exame crítico mais profundo.

Por tudo, é extremamente importante que a pesquisa jurídica avance, com maior interesse e agilidade, em temas sensíveis referentes à inovação, disponibilizando, assim, substratos para que legisladores e reguladores possam efetivamente compreender as razões intrínsecas dos novos modelos e suas reais consequências para a comunidade.

Somente assim a produção normativa poderá, (i) ser suficientemente estável e previsível para transmitir confiança e segurança aos empreendedores e consumidores, garantindo um adequado balanço entre inovação e outros valores a serem tutelados pelo ordenamento, endereçando, de forma apropriada, eventuais externalidades negativas geradas pelas plataformas inovadoras; e (ii) pretender não se distanciar da realidade, em última instância estabelecendo uma estrutura institucional que crie desincentivos à criação de novos produtos e serviços.

\section{REFERÊNCIAS}

ANGELUCCI, Manuela; DI MARO, Vincenso. Program evaluation and spillover effects. Ann Arbor: IZA, 2015. Discussion Paper No. 9033. 
ASHFORD, Nicholas A; AYERS, Christine; STONE, Robert F. Using regulation to change the market for innovation. Harvard Environmental Law Review, Harvard, v. 9, 1985, p. 419-466.

BARRY, Jordan M.; CARON, Paul L. Tax regulation, transportation innovation, and the sharing economy. The University of Chicago Law Review Dialogue, Chicago, v. 82, n. 69, p. 69-84, 2015.

DE SOTO, Hernando. The mystery of capital: why capitalism succeeds in the west and fail everywhere else. London: Black Swan Books, 2001.

DYAL-CHAND, Rashmi. Regulating sharing: the sharing economy as an alternative capitalist system. Tulane Law Review, New Orleans, v. 90 , n. 2, p. 241-309, 2015.

FIANI, Ronaldo. Teoria da regulação econômica: Estado atual e perspectivas futuras. 1998, Disponível em: <www.ir.ufrj.br/gre/pdf $>$. Acesso em: 27 ago. 2016.

FOCHEZATTO, Adelar; VALENTINI, Paulo Juliano. Economias de aglomeração e crescimento econômico regional: um estudo aplicado ao Rio Grande do Sul usando um modelo econométrico com dados de painel. Economia, Niterói, p. 243-266, dez. 2010.

GAUTHIER, Gustavo (Coord.). Disrupción, economía compartida y derecho: enfoque jurídico multidisciplinario. Montevideo: Fundación de Cultura Universitaria, 2016.

HOESCHELE, Wolfgang. Role of commons and common property in an economy of abundance. 2011. Disponível em: $<$ http://wiki. p2pfoundation.net/Role_of_the_Commons_and_Common_Property_ in_an_Economy_of_Abundance $>$. Acesso em: 26 ago. 2016 .

JEHLE, Geoffrey; RENY, Phillip. Advanced microeconomic theory. New Jersey: Prentice Hall, 2011. 
KATZ, Vanessa. Regulating the sharing economy. Berkeley

Technology Law Journal, Berkeley, v. 30, p. 1.066-1.126, 2015.

KOOPMAN, Christopher; MITCHELL, Matthew; THIERER, Adam. The sharing economy and consumer protection regulation: the case for policy change. The Journal of Business, Entrepreneurship \& Law, Malibu, v. 8, p. 530-545, 2015.

LISTOKIN, Yair. Learning through policy variation. Yale Law School Scholarship Repository, Yale, p. 480-553, 2008.

MANKIW, N. Gregory. Principles of economics. Stamford: Cengage Lerning, 2015.

MOREY, Edward. An introduction to market failures. 2015.

Disponível em: <http://www.colorado.edu/economics/morey/4545/ introductory/marketfailures.pdf $>$. Acesso em: 27 ago. 2016.

POSEN, Hannah A. Ridesharing in the sharing economy: should regulators impose Über regulations on Uber? Iowa Law Review, Iowa, v. 101, p. 405-433, 2015.

RANCHORDÁS, Sofia. Does sharing mean caring? Regulating innovation in the sharing economy. Minnesota Journal of Law, Science and Technology, Minnesota, v. 16, 2015, p. 413-476.

RASSMAN, Catherine L. Regulating rideshare without stifling innovation: examining the drivers, the insurance "gap", and why Pennsylvania should get on board. Pittsburgh Journal of Technology Law \& Policy, Pennsylvania, v. 15, 2014, p. 81-100.

STEWART, Richard B. Regulation, innovation and administrative law: a conceptual framework. California Law Review, California, v. 69, n. 5, p. 1.256-1.377, 1981.

WHITT, Richard S. Adaptative policymaking: evolving and applying 
emergent solutions for U.S. Communications Policy. Federal

Communications Law Journal, Washington, v. 61, p. 483-590, 2009.

Como citar: SILVA, Raphael Andrade; PAIVA, Matheus Silva de; DINIX, Gustavo Saad. Desafios Jurídico-Regulatorios e Economia Compartilhada: Elementos para uma Reflexão Crítica. Scientia Iuris, Londrina, v. 21, n. 2, p. 98-125, jul. 2017. DOI: 10.5433/2178-8189.2017v21n1p98. ISSN: 2178-8189.

Recebido em: 20/09/2016

Aprovado em: 06/06/2017 